\title{
Factors for Culling Risk due to Pregnancy Failure in Breeding-Female Pigs
}

\author{
Satomi Tani ${ }^{1} \&$ Yuzo Koketsu ${ }^{1}$ \\ ${ }^{1}$ School of Agriculture, Meiji University, Kawasaki, Japan \\ Correspondence: Yuzo Koketsu, School of Agriculture, Meiji University, Higashi-mita 1-1-1, Tama-ku, \\ Kawasaki, Kanagawa 214-8571, Japan. Tel: 81-44-934-7826. E-mail: koket001@isc.meiji.ac.jp
}

Received: August 11, 2016

Accepted: October 2, $2016 \quad$ Online Published: December 15, 2016

doi:10.5539/jas.v9n1p109

URL: http://dx.doi.org/10.5539/jas.v9n1p109

The research is financed by Research Project Grants (Giken A 2012-2016) and Graduate School GP 2016 from Meiji University.

\begin{abstract}
A high occurrence of culling due to pregnancy failure disturbs the flow of pig production and decreases productivity of female pigs in commercial breeding herds. The objective of the present study was to quantify changes in culling risk due to pregnancy failure [CRPF] in breeding-female pigs due to variation in outdoor climate and production factors. The data included 240143 parity records and 54858 lifetime records of female pigs in 99 commercial herds located in humid subtropical and continental climate zones. The weather data were acquired from 21 local meteorological observatories close to the studied herds. Mean daily average temperature [Tmean] and relative humidity $[\mathrm{RH}]$ during the 21-day pre-mating period for each female were matched with the female's reproductive data. Generalized linear mixed-effects models were applied to the data. Mean by-parity and lifetime CRPF ( \pm SE) were $3.6 \pm 0.04 \%$ and $20.1 \pm 0.17 \%$, respectively. An increase in by-parity CRPF was associated with higher Tmean, higher gilt age at first-mating, fewer pigs born alive and prolonged weaning-to-first-mating interval $(\mathrm{P}<0.05)$, but not with mean $\mathrm{RH}(\mathrm{P} \geq 0.18)$ or weaning age $(\mathrm{P} \geq 0.31)$. For instance, CRPFs for female pigs in parities $0-5$ were $1.5-2.4 \%$ higher at Tmean $30{ }^{\circ} \mathrm{C}$ than at $10{ }^{\circ} \mathrm{C}(\mathrm{P}<0.05)$. Therefore, producers are recommended to closely monitor at-risk female pigs and apply advanced cooling equipment to reduce heat stress, and provide appropriate management to prevent increased CRPF in female pigs.
\end{abstract}

Keywords: pregnancy failure, culling risk, outdoor climate change, pigs born alive, epidemiology

\section{Introduction}

Reproductive failure, including pregnancy failure and anestrus, is a major reason for culling of breeding-female pigs in commercial swine herds (Lucia Jr. et al., 2000; Engblom et al., 2007), with approximately 25\% of mated females culled due to reproductive failure in USA (USDA, 2015). Culling due to pregnancy failure is more problematic than culling due to anestrus because weaning-to-culling intervals and non-productive days are higher in mated females than those in unmated females (Koketsu, 2005). Also, a high occurrence of culling due to pregnancy failure disturbs the stable flow of pig produced by females in a pig production system, and decreases the overall productivity of females in a commercial breeding herd (Koketsu et al., 1999). However, there is little reported information about factors relating to either culling risk due to pregnancy failure [CRPF], or culling interval for females culled due to pregnancy failure.

Low farrowing rate and late pregnancy loss have been associated with high gilt age at first-mating [AFM], low weaning age, high or low parity, prolonged weaning-to-first-mating interval and summer serving (Takai \& Koketsu, 2007; Bertoldo et al., 2009). Furthermore, the association between outdoor temperature and low farrowing rate has been well studied (Bloemhof et al., 2008; Iida \& Koketsu, 2016). For example, outdoor temperature has been associated with a lower farrowing rate in specific purebred lines in Spain (Bloemhof et al., 2008). In addition, increased outdoor temperature during the 21-day pre-mating period decreased farrowing rates in all parity groups (Iida \& Koketsu, 2016). From these reports, it was hypothesized that pre-mating outdoor temperature can increase CRPF in commercial herds because farrowing failure affects culling decisions by the producers. In addition, sows farrowing fewer pigs born alive are more likely to be culled (Iida \& Koketsu, 2014). 
Also, a prolonged weaning-to-first-mating interval would affect their culling decision because those sows would have a low farrowing rate or few pigs born (Koketsu, 1997). Therefore information about quantified associations between CRPFs and climatic or production factors could help veterinarians or producers to predict how CRPF is likely to increase, especially because they could obtain information about outdoor temperatures from local weather news. However, no studies have quantified the associations between by-parity CRPF changes in outdoor climate and production factors such as AFM, weaning-to-first-mating interval and the number of pigs born alive in the same model. Therefore, the objective of this study was to quantify how variation in outdoor climate and production factors changes CRPF in commercial herds located in humid subtropical and continental climate zones.

\section{Materials and Methods}

\subsection{Herds}

Swine producers of 101 Japanese commercial herds that use the PigCHAMP recording system (PigCHAMP, Ames, IA, USA) were requested to mail their data files to Meiji University in 2011. Data files were received from all producers by August 31, 2011. Two of the herds were excluded from the study because they were producing only purebred pigs. Hence, data from 99 herds were analyzed.

The 99 herds throughout Japan were located between latitude $30-45^{\circ} \mathrm{N}$ and longitude $130-145^{\circ} \mathrm{E}$. They used either natural ventilation or mechanical ventilation in their farrow-to-wean systems. Also, the diets for lactation and gestation were formulated using imported corn and soybean meal with diet formulations based on National Research Council (2012). Artificial insemination was used in $90 \%$ of the studied herds. At approximately day 30 of pregnancy, $70 \%$ of the herds used real-time ultrasound apparatus, while the remaining $30 \%$ used either echo or Doppler ultrasound apparatus. Female pigs in the herds were either crossbreds between Landrace and Large White from national breeding companies (approximately 70\%) or crossbred pigs from international breeding companies. Replacement gilts were either purchased or were home-produced through internal multiplication programs. The breeding stocks in the national breeding companies were originally introduced from the U.S.A. or Europe from 1960, and the pure lines have been improved in Japan.

\subsection{Definitions and Categories}

When female pigs were culled from the herds, the producers recorded the reasons for culling. Reasons for culling due to pregnancy failure included failure to farrow, did not conceive, found not pregnant, pregnancy check negative, and abortion. All female pigs that were culled due to pregnancy failure were confirmed as having had a mating event in the culled parity.

A gilt was defined as a female pig that had entered a herd but had not yet farrowed, and a sow was a female pig that had farrowed at least once. By-parity CRPF (\%) was defined as the number of female pigs culled due to pregnancy failure divided by the number of female pigs mated at that parity $\times 100$. Lifetime CRPF $(\%)$ was defined as the number of female pigs culled due to pregnancy failure divided by the number of first-mated gilts $\times$ 100. Service records were categorized into two groups of weaning-to-first-mating intervals: 0-6 days and 7 days or more.

\subsection{Data and Exclusion Criteria}

Female pigs were entered into the herds from 2005 to 2007 and were subsequently mated from 2005 to 2010 . The data of female pigs extracted from the stored record in PigCHAMP produced a database that included 56 088 lifetime records and 283673 parity records of female pigs. At the time of data collection, 922 of the female pigs $(1.6 \%)$ had not been yet removed from the herds, and so their data were excluded. Female pigs were also excluded if they did not have records of removal type ( 171 female pigs), or if they had a last-mating-to-culling interval of either less than 11 days ( 23 female pigs) or more than 175 days (114 female pigs). The 175 days value was the $99^{\text {th }}$ percentile of the last-mating-to-culling interval record.

With regard to parity records, parity 6 or higher records were excluded because most of the sows in these parities were voluntarily culled as "high parity" (34 119 records). In addition, sow parity records were excluded if they met any of the following criteria (Hoving et al., 2011): 0 total pigs born (27 records); weaning ages of either 0-9 days or more than 40 days (1533 records); number of pigs weaned being three or less (1926 records) or 17 or more pigs (4483 records), or a weaning-to-first-mating interval of 36 days or more (3161 records). Also, AFM records of either less than 160 days or more than 400 days were not used when a variable of AFM was included in the models (16,752 records). Hence, the final dataset included 54,858 lifetime records and 240,143 parity records. 
Additionally, herd measurement data were abstracted from the 99 herd data files for six one-year periods from 2005 to 2010 . Mean ( \pm SEM) herd size was $427 \pm 57.8$ female pigs, ranging between 49 and 3618 female pigs. Mean $( \pm$ SEM) weaning ages for sows was $21.3( \pm 0.01)$ days.

\subsection{Climate Data}

Average daily temperature and relative humidity data from 2005 to 2010 were acquired from the meteorological records of 21 local meteorological observatories of the Japan Meteorological Agency (2014). The local meteorological observatories were located in the local government office cities of the 21 prefectures where the studied herds were sited. The studied herds were located in either humid subtropical (94 herds) or humid continental climate zones (5 herds) according to the Köppen climate classification (Peel et al., 2007). Mean ( \pm SEM) distance from each herd to the relevant meteorological observatory was $44.2 \pm 2.7 \mathrm{~km}$.

Mean average daily temperature [Tmean] and average relative humidity $[\mathrm{RH}]$ for the 21-day pre-mating period of each female pig were matched with respective performance data from the PigCHAMP records. This 21-day period was chosen because a previous study has indicated that heat stress between 14 and 21 days before first-insemination has the largest effect on farrowing rate (Bloemhof et al., 2013). Additionally, the 21-day pre-mating period includes a large part of the lactating period in sows.

\subsection{Statistical Analysis}

All statistical analyses were performed using a commercial statistical package (SAS 9.3, SAS Institute Inc. Cary, $\mathrm{NC}$, USA). All the analyses were done by parity. In order to examine the associations between CRPF, changes in outdoor climate and production factors, a generalized linear mixed-effects model was applied to binary outcome in the model, i.e. whether or not a female pig was culled due to pregnancy failure (1 or 0), using the GLIMMIX procedure with Ilink (inverse link function). The Models contained Tmean, RH and the entry year as fixed effects. The models were two-level using a herd as level 2 and an individual record as level 1.

The AFM was included in the models when data of parity 0-2 females were analyzed because AFM was reported to be associated with reproductive performance in parity 0-2 female pigs (Schukken et al., 1994). In addition, the following factors were added when the sows' data were analyzed: the number of pigs born alive, weaning-to-first-mating interval and weaning age. All the continuous explanatory factors were centered at their grand mean values. The quadratic expressions of continuous factors were examined, and non-significant factors and expressions were removed $(\mathrm{P} \geq 0.10)$. A random herd effect within a herd was also included in both models.

The Ilink function option was also used to convert the logit to a probability (Littell et al., 2006) and to generate figures. Normality of the residuals for the random effects in each of the final models was assessed by using normal probability plots (Littell et al., 2006).

\subsection{Intraclass Correlation Coefficients}

To evaluate the variation in the CRPF that could be explained by the herd, the intraclass correlation coefficients [ICC] were calculated by Equation (1) (Dohoo et al., 2009):

$$
\text { ICC (individual records within the same herd) }=\sigma_{v}{ }^{2} /\left(\sigma_{v}{ }^{2}+\left(\pi^{2} / 3\right)\right)
$$

Where, $\sigma_{v}{ }^{2}$ is the between-herd variance, and $\pi^{2} / 3$ is the assumed variance at the female record level.

\section{Results}

Mean by-parity CRPF ( \pm SE) and lifetime CRPF were $3.6 \pm 0.04 \%$ and $20.1 \pm 0.17 \%$, respectively. Mean $( \pm$ SE) last-mating-to-culling interval for pigs culled due to pregnancy failure was $61.2 \pm 0.34$ days (Table 1). Mean values (ranges) of daily average temperature and daily average relative humidity were $15{ }^{\circ} \mathrm{C}$ (range: -10.7 to $32.7^{\circ} \mathrm{C}$ ) and $68.5 \%$ (range: 19 to $99 \%$ ), respectively. 
Table 1. Reproductive data for female pigs in 99 herds

\begin{tabular}{|c|c|c|c|c|}
\hline \multirow{2}{*}{ Measurements } & \multirow{2}{*}{$\mathrm{N}$} & \multirow{2}{*}{ Mean \pm SEM } & \multicolumn{2}{|c|}{ Range } \\
\hline & & & Minimum & Maximum \\
\hline \multicolumn{5}{|l|}{ Lifetime records } \\
\hline Parity at culling & 54,858 & $4.8 \pm 0.01$ & 0 & 13 \\
\hline Gilt age at first-mating, days old & 50,938 & $245.7 \pm 0.12$ & 160 & 400 \\
\hline Last-mating-to-culling interval for pregnancy failure, days & 11,042 & $61.2 \pm 0.34$ & 11 & 175 \\
\hline Lifetime CRPF, \% & 54,858 & $20.1 \pm 0.17$ & - & - \\
\hline \multicolumn{5}{|l|}{ Parity records } \\
\hline Mated parity & 240,143 & $2.1 \pm 0.01$ & 0 & 5 \\
\hline CRPF per mating, $\%$ & 240,143 & $3.6 \pm 0.04$ & - & - \\
\hline Number of pigs born alive, pigs & 185,285 & $11.0 \pm 0.01$ & 0 & 24 \\
\hline Weaning age, days & 185,285 & $21.3 \pm 0.01$ & 10 & 41 \\
\hline Weaning-to-first-mating interval, days & 185,285 & $6.2 \pm 0.01$ & 0 & 35 \\
\hline
\end{tabular}

Note. $\mathrm{CRPF}=$ culling risk due to pregnancy failure; ${ }^{1}$ The remaining records $(240,143-\mathrm{N})$ were regarded as missing records.

Table 2 shows the estimates of the factors in the final logistic regression models for CRPF of female pigs in parities 0 to 5. In parities, a higher CRPF was associated with higher Tmean, higher AFM, fewer pigs born alive and a weaning-to-first-mating interval of 7 days or more $(\mathrm{P}<0.05)$, but it was not associated with relative humidity $(\mathrm{P} \geq 0.18)$ or weaning age $(\mathrm{P} \geq 0.31)$.

Table 2. Estimates of factors in the final logistic regression models for culling risk due to pregnancy failure of female pigs in parities 0 to 5

\begin{tabular}{|c|c|c|c|}
\hline \multirow{2}{*}{ Fixed and random effects ${ }^{1}$} & Parity 0 & Parity 1 & Parity 2 \\
\hline & Estimate $( \pm \mathrm{SE})$ & Estimate $( \pm \mathrm{SE})$ & Estimate $( \pm \mathrm{SE})$ \\
\hline Intercept & $-3.400(0.071)^{* *}$ & $-3.449(0.117)^{* *}$ & $-3.236(0.121)^{* *}$ \\
\hline Tmean, ${ }^{\circ} \mathrm{C}$ & $0.012(0.004)^{* *}$ & $0.015(0.005)^{* *}$ & $0.017(0.005)^{* *}$ \\
\hline Tmean x Tmean & - & $0.002(0.001)^{* *}$ & $0.001(0.0005)^{*}$ \\
\hline AFM, days old & $0.006(0.001)^{* *}$ & $0.004(0.001)^{* *}$ & $0.0004(0.00160)$ \\
\hline AFM x AFM & - & - & $0.0001(0.00001)^{*}$ \\
\hline Number of pigs born alive, pigs & - & $-0.046(0.009)^{* *}$ & $-0.029(0.010)^{* *}$ \\
\hline WMI 0-6 days & - & $-0.458(0.066)^{* *}$ & $-0.702(0.078)^{* *}$ \\
\hline Herd variance & $0.35(0.07)$ & $0.58(0.11)$ & $0.45(0.09)$ \\
\hline ICC (records within the same herd), \% & 9.4 & 14.6 & 11.8 \\
\hline \multirow{2}{*}{ Fixed and random effects ${ }^{1}$} & Parity 3 & Parity 4 & Parity 5 \\
\hline & Estimate $( \pm \mathrm{SE})$ & Estimate $( \pm \mathrm{SE})$ & Estimate $( \pm \mathrm{SE})$ \\
\hline Intercept & $-2.977(0.120)^{* *}$ & $-2.804(0.115)^{* *}$ & $-2.286(0.117)^{* *}$ \\
\hline Tmean, ${ }^{\circ} \mathrm{C}$ & $0.015(0.0050)^{* *}$ & $0.014(0.005)^{* *}$ & $0.013(0.0040)^{* *}$ \\
\hline Tmean x Tmean & $0.001(0.0005)^{*}$ & $0.002(0.001)^{* *}$ & $0.001(0.0005)^{*}$ \\
\hline Number of the pigs born alive, pigs & $-0.062(0.011)^{* *}$ & $-0.057(0.010)^{* *}$ & $-0.055(0.009)^{* *}$ \\
\hline Number of the pigs born alive-squared & $0.004(0.002)^{*}$ & $0.005(0.002)^{* *}$ & - \\
\hline WMI 0-6 days & $-0.727(0.080)^{* *}$ & $-0.769(0.080)^{* *}$ & $-0.847(0.084)^{* *}$ \\
\hline Herd variance & $0.47(0.09)$ & $0.35(0.08)$ & $0.38(0.08)$ \\
\hline ICC (records within the same herd), \% & 12.2 & 9.5 & 10.1 \\
\hline
\end{tabular}

Note. ${ }^{1} \mathrm{SE}=$ standard error; Tmean $=$ mean daily average temperature; $\mathrm{AFM}=$ gilt age at first-mating; WMI $=$ weaning-to-first-mating interval; ICC $=$ intraclass correlation coefficient; * indicates $0.01 \leq \mathrm{P}<0.05$; ** indicates $\mathrm{P}<0.01$. 
The effects of Tmean, AFM and numbers of pigs born alive on predicted CRPF (\%) of female pigs in the different parities are shown in Figures 1, 2 and 3, respectively. However, the association varied between parities. For instance, as Tmean increased from 10 to $30{ }^{\circ} \mathrm{C}$, the CRPF for gilts increased linearly by $0.5 \%$, whereas the CRPF for sows in parities $1-5$ showed a quadratic increase of $1.5-2.4 \%(\mathrm{P}<0.05)$. Furthermore, when AFM increased from 220 to 300 days the CRPF for gilts increased by $2.1 \%$, whereas for sows in parities 1 and 2 it increased by only $0.7-0.9 \%(\mathrm{P}<0.05)$. With regard to pigs born alive, as the number decreased from 14 to 4 pigs the CRPFs in parities 3, 4 and 5 increased by $2.4-3.0 \%$, whereas in parities 1 and 2 it increased by only 0.9 and $0.6 \%$, respectively $(\mathrm{P}<0.05)$.

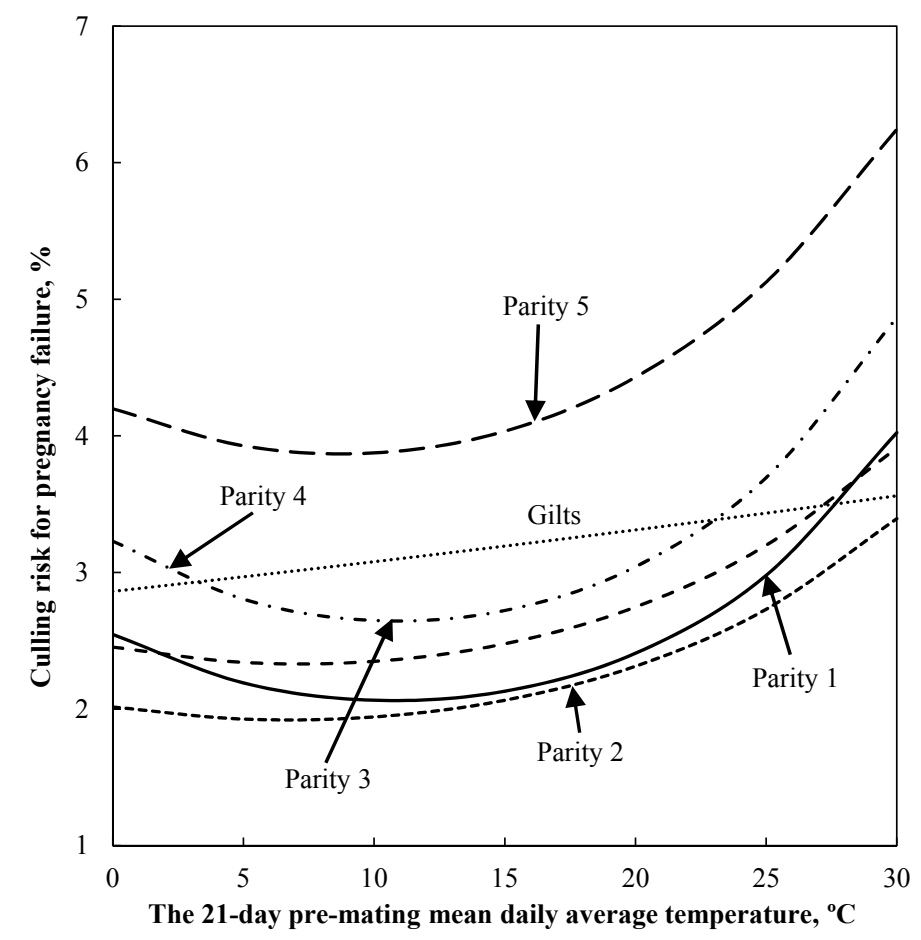

Figure 1. Effect of the 21-day pre-mating mean daily average temperature on predicted culling risk due to pregnancy failure of female pigs in different parities 


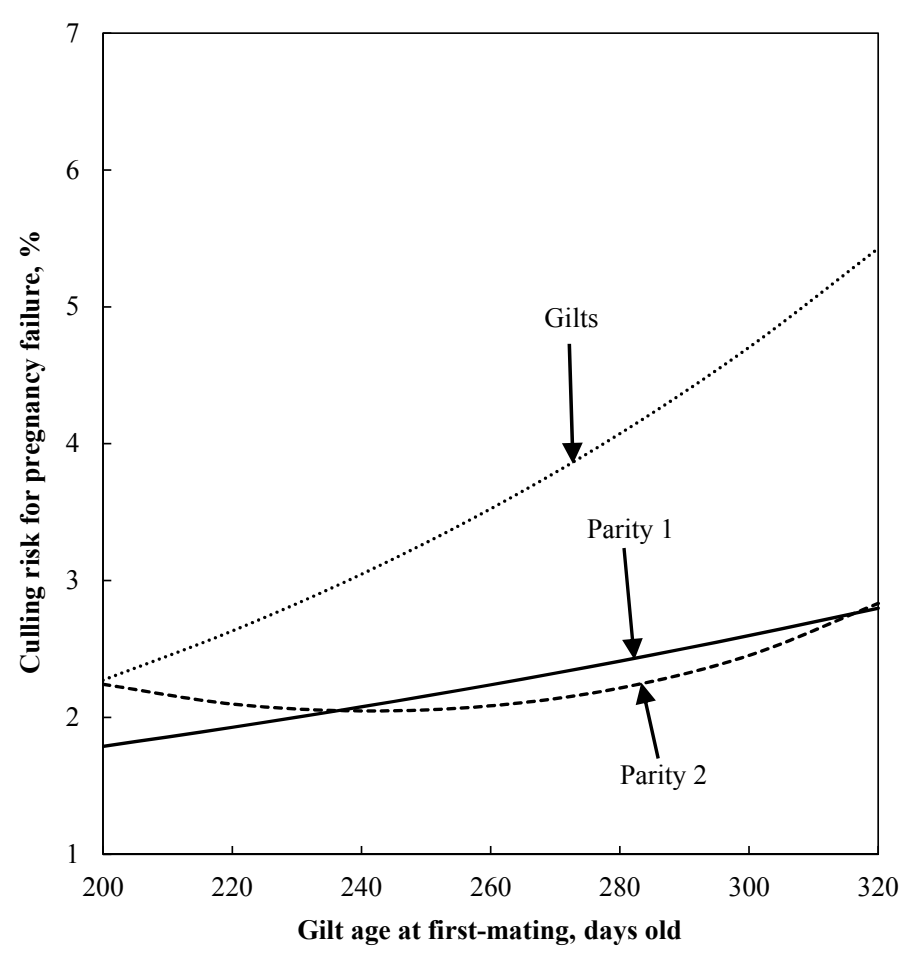

Figure 2. Effect of gilt age at first-mating on predicted culling risk due to pregnancy failure of female pigs in different parities

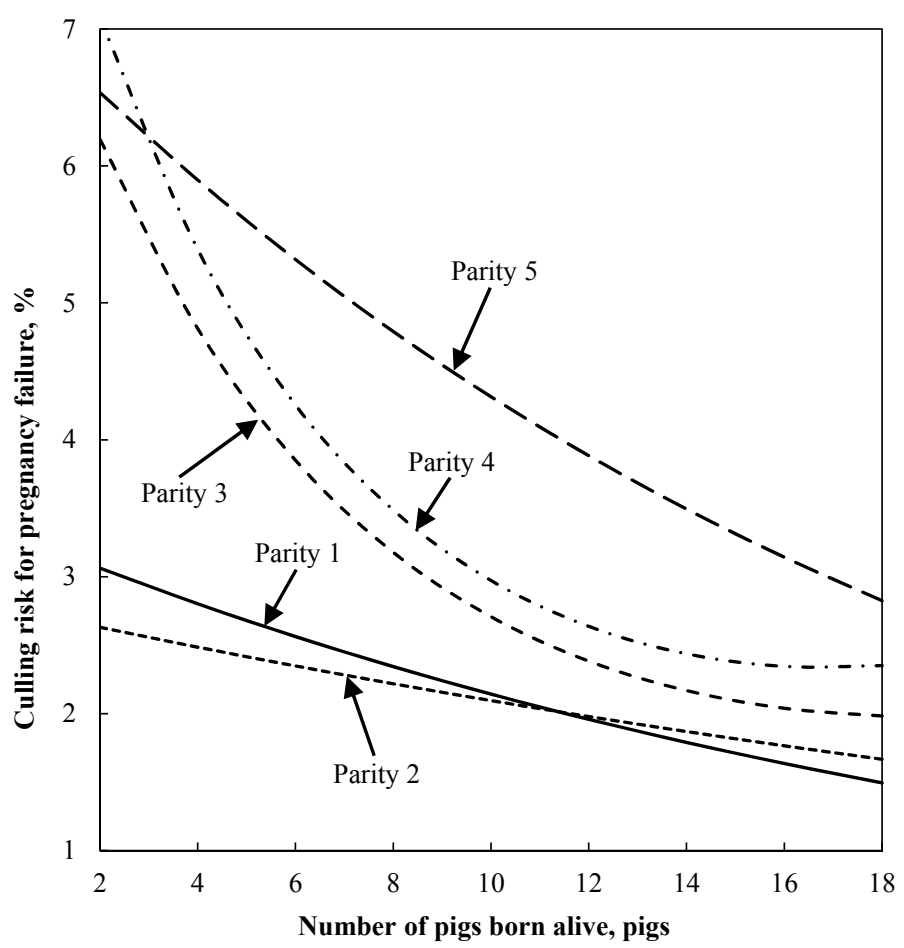

Figure 3. Effect of the number of pigs born alive on predicted culling risks due to pregnancy failure of female pigs in different parities 
Table 3 shows comparisons of CRPF (\%) between two weaning-to-first-mating interval groups at different parities. The CRPFs of sows in parities 1-5 that had a weaning-to-first-mating interval of 7 days or more were $1.2-4.9 \%$ higher than those of sows which had a weaning-to-first-mating interval of only $0-6$ days $(\mathrm{P}<0.05)$. Additionally, there was no two-way interaction between Tmean and either relative humidity or any of the other production factors for CRPF ( $\mathrm{P} \geq 0.10)$. Finally, the ICC analysis showed that the random herd effect explained 9.4-14.6\% of the total variation for CRPF.

Table 3. Comparisons of culling risk due to pregnancy failure (\%) in different parities between two weaning-to-first-mating interval groups

\begin{tabular}{|c|c|c|c|}
\hline \multirow{3}{*}{ Parity } & \multirow{3}{*}{$\mathrm{N}$} & \multicolumn{2}{|c|}{ Culling risk (\%) by weaning-to-first-mating interval } \\
\hline & & $0-6$ days & 7 days or later \\
\hline & & Mean $( \pm \mathrm{SE})$ & Mean $( \pm$ SE $)$ \\
\hline 1 & 54,858 & $2.2(0.20) \mathrm{b}$ & $3.4(0.34) \mathrm{a}$ \\
\hline 2 & 44,163 & $2.1(0.18) b$ & $4.1(0.41) \mathrm{a}$ \\
\hline 3 & 41,600 & $2.5(0.21) \mathrm{b}$ & $4.9(0.50) \mathrm{a}$ \\
\hline 4 & 37,618 & $2.9(0.22) b$ & $6.1(0.58) \mathrm{a}$ \\
\hline 5 & 33,440 & $4.0(0.30) \mathrm{b}$ & $8.9(0.85) \mathrm{a}$ \\
\hline
\end{tabular}

Note. $\mathrm{SE}=$ standard error; ${ }^{\mathrm{a}, \mathrm{b}}$ Mean values within a row followed by different letters differ $(\mathrm{P}<0.05)$.

\section{Discussion}

The increase in CRPF between parities 2 and 5, indicates that producers increase their culling pressure on mated sows during these parities. Overall, the $20 \%$ lifetime CRPF in our study is quite similar to the $24.5 \%$ value found in a previous study in North America by Lucia Jr. et al. (2000). Furthermore, the higher CRPF for sows in parities $1-5$ exposed to $30^{\circ} \mathrm{C}$ than those exposed to $10{ }^{\circ} \mathrm{C}(0.8-2.3 \%)$ is supported by another study that showed that high temperature in summer was associated with lower farrowing rate due to pregnancy failure (Bloemhof et al., 2008).

We also found that in sows there was a quadratic increase in CRPF as pre-service Tmean increased, whereas in gilts the increase in CRPF was linear. It is likely that this difference between the two groups can be explained by high temperatures decreasing the lactational feed consumption of sows in summer (Koketsu \& Dial, 1997). Such a decrease in feed consumption would likely increase the occurrence of pregnancy failure and CRPF in sows because it damages follicle development during lactation and post weaning, as well as subsequently lowering corpora lutea functions that results in low progesterone concentrations (Bertoldo et al., 2012) and increases pregnancy failure. Furthermore, the quadratic increase in sow CRPF due to increased temperatures in our study indicates that the CRPF started increasing more rapidly at around $20{ }^{\circ} \mathrm{C}$. These results agree with those from a previous study in Spain which showed that the upper critical temperature for farrowing rate in sows was approximately $19^{\circ} \mathrm{C}$, i.e., the temperature above which farrowing rate started to decrease (Bloemhof et al., 2008), and that such decreased farrowing rates could increase the CRPF. High RH has also been shown to accentuate the negative effect of higher Tmean on the number of total pigs born in sows (Iida \& Koketsu, 2014). However, we did not find any major effect of RH around the 21-day pre-mating period on CRPF, either in the humid subtropical or humid continental climate zone.

The association that we found between high AFM and increased CRPF in gilts and young sows could be due to the fact that gilts with high AFM are likely to have immature or delayed maturation of endocrine systems. Such a situation would mean that they would be more likely to have conception failure or be less able to maintain pregnancy, i.e. have innately low fertility (Vargas et al., 2009).

Our study indicated that high parity sows with few pigs born alive have a higher risk of being culled due to pregnancy failure. In particular, sows in parities 3-5 had high CRPF. However, a previous study did not find that fewer pigs born alive was associated with either prolonged lifetime weaning-to-first-mating interval or lifetime non-productive days (Iida \& Koketsu, 2014), both of which decrease sow productivity. Additionally, parity 5 sows usually have a better farrowing rate and more pigs born alive than gilts (Iida \& Koketsu, 2015). Therefore, it appears that that it would be better if sows in parities 3-4 with fewer pigs born alive are not culled unless they have a locomotor problem or a disease. 
The association in our study between higher CRPF and prolonged weaning-to-first-mating interval is consistent with a previous study showing an increased chance of pregnancy loss in sows with a prolonged weaning-to-first-mating interval (Bertoldo et al., 2009). In order to reduce the number of sows with a weaning-to-first-mating interval of 7 days or more, feed consumption for lactating sows should be increased (Koketsu et al., 1996). Finally, the ICC of 8.2-13.7\% indicates that there were some effects of the herd on CRPF, such as pregnancy check accuracy or culling policy difference.

The lack of any association between low weaning age and CRPF in our study is not consistent with the results of a previous study which showed an association between occurrence of late pregnancy loss and low weaning age (Bertoldo et al., 2009). One of the reasons for this discrepancy is probably that our dataset did not include many sows with a weaning age of 13 days or lower (637 records: $0.26 \%$ ). Additionally, some of the variation in weaning age could have been explained by the herd effect in our models, because weaning age is related to herd management and the herd effect.

In conclusion, we recommend that producers use some cooling systems (e.g., evaporative coolers) more frequently to reduce heat stress, and also that they provide appropriate care for mated female pigs, especially that they closely monitor female pigs at risk of having pregnancy failure.

There are some limitations in our observational study conducted by using commercial herd data and climate data recorded at local weather stations. Housing, nutrition, herd health and genotype were not considered in our models. However, some of the herd variations can be explained by our two-level models having a random herd effect. Even with such limitations, this study delivers useful information for pig producers and their veterinarians about the relationship between CRPF, outdoor temperature and other production factors.

\section{Acknowledgements}

The authors acknowledge the pig producers for providing their data for use in the present study. We thank Dr. I. McTaggart for his critical review of this manuscript.

\section{References}

Bertoldo, M. J., Holyoake, P. K., Evans, G., \& Grupen, C. G. (2012). Seasonal variation in the ovarian function of sows. Reproduction, Fertility and Development, 24, 822-834. http://dx.doi.org/10.1071/RD11249

Bertoldo, M., Grupen, C., Thomson, P., Evans, G., \& Holyoake, P. (2009). Identification of sow-specific risk factors for late pregnancy loss during the seasonal infertility period in pigs. Theriogenology, 72, 393-400. http://dx.doi.org/10.1016/j.theriogenology.2009.03.008

Bloemhof, S., Mathur, P. K., Knol, E. F., \& van der Waaij, E. H. (2013). Effect of daily environmental temperature on farrowing rate and total born in dam line sows. Journal of Animal Science, 91, 2667-2679. http://dx.doi.org/10.2527/jas.2012-5902

Bloemhof, S., van der Waaij, E. H., Merks, J. W., \& Knol, E. F. (2008). Sow line differences in heat stress tolerance expressed in reproductive performance traits. Journal of Animal Science, 86, 3330-3337. http://dx.doi.org/10.2527/jas.2008-0862

Dohoo, I. R., Martin, S. W., \& Stryhn, H. (2009). Veterinary Epidemiologic Research (2nd ed.). VER Inc. Charlottetown, Prince Edwards Island, Canada.

Engblom, L., Lundeheim, N., Dalin, A.-M., \& Andersson, K. (2007). Sow removal in Swedish commercial herds. Livestok Science, 106, 76-86. http://dx.doi.org/10.1016/j.livsci.2006.07.002

Hoving, L. L., Soede, N. M., Graat, E. A. M., Feitsma, H., \& Kemp, B. (2011). Reproductive performance of second parity sows: Relations with subsequent reproduction. Livestok Science, 140, 124-130. http://dx.doi.org/10.1016/S0301-6226(98)00176-6

Iida, R., \& Koketsu, Y. (2014). Interactions between pre-or postservice climatic factors, parity, and weaning-to-first-mating interval for total number of pigs born of female pigs serviced during hot and humid or cold seasons. Journal of Animal Science, 92, 4180-4188. http://dx.doi.org/10.2527/ jas.2014-7636

Iida, R., \& Koketsu, Y. (2015). Number of pigs born alive in parity 1 sows associated with lifetime performance and removal hazard in high-or low-performing herds in Japan. Preventive Veterinary Medicine, 121, 108-114. http://dx.doi.org/10.1016/j.prevetmed.2015.06.012

Iida, R., \& Koketsu, Y. (2016). Lower farrowing rate in female pigs associated with higher outdoor temperatures in humid subtropical and continental climate zones in Japan. Animal Reproduction, 13(2), 63-68. http://dx.doi.org/10.21451/1984-3143-AR728 
Japan Meteorological Agency. (n.d.). Climate Statistics (Japanese). Retreived January 1, 2014, from http://www.data.jma.go.jp/gmd/risk/obsdl/index.php

Koketsu, Y. (2005). Six component intervals of nonproductive days by breeding-female pigs on commercial farms. Journal of Animal Science, 83, 1406-1412. http://dx.doi.org/10.2527/jas.2005.8361406x

Koketsu, Y., \& Dial, G. D. (1997). Factors influencing the postweaning reproductive performance of sows on commercial farms. Theriogenology, 47, 1445-1461. http://dx.doi.org/10.1016/S0093-691X(97)00135-0

Koketsu, Y., Dial, G. D., Pettigrew, J. E., \& King, V. L. (1996). Feed intake pattern during lactation and subsequent reproductive performance of sows. Journal of Animal Science, 74, 2875-2884. http://dx.doi.org/ $10.2527 /$ jas. $1996.74122875 \mathrm{x}$

Koketsu, Y., Duangkaew, C., Dial, G. D., \& Reeves, D. (1999). Within-farm variability in number of females mated per week during a one-year period and breeding herd productivity on swine farms. Journal of the American Veterinary Medical Association, 214, 520-524.

Littell, R. C., Milliken, G. A., Stroup, W. W., Wolfinger, R. D., \& Schabenberger, O. (2006). SAS for Mixed Models (2nd ed.). SAS Institute Inc. Cary, NC, USA.

Lucia Jr., T., Dial, G. D., \& Marsh, W. E. (2000). Lifetime reproductive performance in female pigs having distinct reasons for removal. Livestock Production Science, 63, 213-222. http://dx.doi.org/10.1016/ S0301-6226(99)00142-6

National Research Council. (2012). Nutrient Requirements of Swine. National Research Council, National Academies Press, Washington, D.C.

Peel, M. C., Finlayson, B. L., \& McMahon, T. A. (2007). Updated world map of the Köppen-Geiger climate classification, Hydrology and Earth System Sciences Discussions, 4, 439-473. http://dx.doi.org/10.5194/ hess-11-1633-2007

Schukken, Y. H., Buurman, J., Huirne, R. B., Willemse, A. H., Vernooy, J. C., Van den Broek, J., \& Verheijden, J. H. (1994). Evaluation of optimal age at first conception in gilts from data collected in commercial swine herds. Journal of Animal Science, 72, 1387-1392. http://dx.doi.org/10.2527/jas.1994.7261387x

Takai, Y., \& Koketsu, Y. (2007). Identification of a female-pig profile associated with lower productivity on commercial farms. Theriogenology, 68, 87-92. http://dx.doi.org/10.1016/j.theriogenology.2007.02.014

USDA. (2015). Swine 2012. USDA-APHIS-VS-NAHMS, Fort Colins, USA. Retreived October 9, 2015, from http://www.aphis.usda.gov/animal-health

Vargas, A. J., Bernardi, M. L., Bortolozzo, F. P., Mellagi, A. P. G., \& Wentz, I. (2009). Factors associated with return to estrus in first service swine females. Preventive Veterinary Medicine, 89, 75-80. http://dx.doi.org/ 10.1016/j.prevetmed.2009.02.001

\section{Copyrights}

Copyright for this article is retained by the author(s), with first publication rights granted to the journal.

This is an open-access article distributed under the terms and conditions of the Creative Commons Attribution license (http://creativecommons.org/licenses/by/4.0/). 